\title{
La historia de la ciencia en la enseñanza de la célula
}

Recibido: 24-11-2010 | Aceptado: 30-06-2011

The history of science in teaching cell

\section{Laura Carrillo*}

Cristina Morales**

Vania Pezoa***

Johanna Camacho
Resumen: A través de este artículo se propone aportar ideas para sustentar la incorporación de la historia de la ciencia en la enseñanza de la biología. Para ello, se realiza una breve reconstrucción histórica y posteriormente, un análisis exploratorio sobre cuáles son los conceptos acerca de la célula que se incorporan en los libros de texto y sí éstos, tienen relación con cómo se construyó la teoría celular. Con esta propuesta se deja en evidencia que los libros de texto, sólo enseñan conceptos sobre la estructura y función de la célula, relacionados principalmente con aportes del Siglo XIX y que poco se promueven conceptos para la comprensión de la célula como unidad hereditaria de origen, estructuras y funciones de los organelos celulares, cuyas propuestas se consolidaron durante el S.XX.

Palabras clave: Historia de la Ciencia, Enseñanza de la Biología, Teoría Celular, Libros de Texto

\begin{abstract}
This article is aimed at providing ideas to support the incorporation of the History of Science in Biology Teaching. Thus the authors decided to present, a brief historical reconstruction and then an exploratory analysis on what concepts of cell are incorporated into textbooks and the relation these textbooks have with the way in which the Cell Theory was constructed. This proposal makes it clear that textbooks only teach concepts about the structure and function of thecell, mainly related to contributions of the nineteenth century and that some concepts are promoted for understanding the cell as inherited origin, structures and functions of cellular organelles, whose proposals were consolidated in the twentieth Century.
\end{abstract}

Keywords: History of Science, Teaching of Biology, Cell Theory, Textbooks, School Biology.

* Licenciada en Educación. Profesora de Biología y Ciencias. Universidad Central de Chile. Correo Electrónico: laura.carrillo.c@gmail.com

* Licenciada en Educación. Profesora de Biología y Ciencias. Universidad Central de Chile. Correo Electrónico: kristinalmorales@gmail.com

*** Licenciada en Educación. Profesora de Biología y Ciencias. Universidad Central de Chile. Correo Electrónico: vani2811@gmail.com

** Doctora en Ciencias de la Educación. Académica e Investigadora Escuela de Pedagogía en Biología y Ciencias Naturales. Facultad de Educación. Universidad Central, Santiago de Chile. Correo Electrónico: jcamachog@ucentral.cl 
La historia de la ciencia en la enseñanza de la célula Laura Carrillo | Cristina Morales | Vania Pezoa | Johanna Camacho

\section{Introducción}

Actualmente, existe un reconocimiento general sobre la importancia de la historia de las disciplinas científicas para su enseñanza (Camacho, 2010). Muchos investigadores del ámbito de la Didáctica de las Ciencias Experimentales (Izquierdo y Adúriz Bravo, 2003; Matthews, 1994; Izquierdo, Vallverdú, Quintanilla y Merino 2006), coinciden en que este aspecto permite comprender cómo ha evolucionado la ciencia en el transcurso del tiempo y cómo las diferentes disciplinas científicas, logran consolidarse en variados contextos socio culturales, por lo que se constituyen en factores relevantes para mejorar la calidad de la enseñanza y aprendizaje.

El principal interés de la incorporación de la historia de la ciencia, no pretende que la enseñanza actual se remplace por una enseñanza de los contenidos históricos, sino que se sugiere intencionar didácticamente este aspecto a fin de comprender cómo se construyen los conocimientos científicos, qué tipo de explicaciones surgen para dar cuenta de dichos conocimientos y qué hace posible sustentar ciertas interpretaciones científicas, promoviendo así que el estudiantado conozca la dinámica de la actividad científica.

A partir de los antecedentes mencionados, se evidencia la necesidad de proponer nuevos objetivos en la enseñanza de las ciencias, que permitan relacionarlas como una actividad profundamente humana en donde interactúan distintos contextos (educación, innovación, evaluación y aplicación), según plantea Echeverría (1995), que permiten su desarrollo y evolución. Desde este punto de vista, este artículo tiene el propósito de aportar ideas para sustentar la incorporación de la Historia de la ciencia en la enseñanza de la biología; para ello, se realiza una breve reconstrucción histórica y posteriormente, un análisis exploratorio sobre cuáles son los conceptos acerca de la célula que se incorporan en los libros de texto y sí éstos, tienen relación con como se construyó la Teoría Celular.

\section{¿Por qué es necesario enseñar historia de la ciencia?}

Considerar los aportes de la historia y de la epistemología de las Ciencias, permiten comprender cómo evolucionan las ciencias a través de un proceso complejo de naturaleza no lineal, riguroso, creativo y que depende del contexto socio cultural (Rivarosa, 2009). Para el estudiantado en ciencias, estos aspectos de indagación de cómo se construye y justifica el conocimiento científico, en particular en el campo de la biología, permiten generar espacios de análisis sobre la naturaleza de la ciencia según Adúriz-Bravo (2000), los cuales permiten estudiar las distintas maneras en que se pueden identificar los problemas; la formulación de hipótesis y estrategias experimentales; las justificaciones metodológicas; la credibilidad y definición de teorías; el análisis crítico de modelos teóricos y prácticos; la ideología y la cultura de la comunidad científica, entre otros, sin asumir un determinismo ingenuo en la práctica investigativa (Rivarosa, 2009).

De este modo, el considerar la historia y la epistemología de las Ciencias desde la organización y definición de modelos teóricos de la biología en distintas épocas y contextos culturales, ofrece la posibilidad de identificar la evolución en las ideas, los marcos teóricos, las estrategias metodológicas y sistemas representacionales (gráficos, signos, símbolos, imágenes) que acompañaron los distintos desarrollos conceptuales (Schuster, 1999), un aporte que consideramos fundamental de tener en cuenta para la enseñanza de las ciencias. 
A continuación se desarrolla una breve reconstrucción histórica del concepto de célula, teniendo en cuenta una visión asincrónica de la ciencia, en donde solamente se consideran los hechos que se consideran relevantes para la formulación de la Teoría Celular. A partir de este análisis, posteriormente se identifican cuáles son los aspectos que se tienen en cuenta en la enseñanza de la biología, a través de los libros de textos que propone el Ministerio de Educación Nacional de Chile (MINEDUC).

\section{Breve reconstrucción histórica de la teoría celular}

La reconstrucción histórica que se presenta a continuación, trata de evidenciar cómo se llevó a cabo la construcción de la teoría celular, los hechos, sucesos, contextos y teorías que surgieron a través de los años. Esta propuesta, se basa fundamentalmente en las recopilaciones de Alzogaray (2006) y Vial (1999).

En primer lugar, se asume que todos los seres vivos están formados por células, algunos por una y otros por billones de éstas; las células son unidades estructurales de los organismos, importantes para el desarrollo de todas las funciones biológicas. Sin embargo, esta afirmación no es tan simple como parece, puesto que existieron varios hechos que llegaron a darle significado. Para comprender cómo estos hechos llegaron a consolidar la Teoría Celular, se presenta el análisis histórico en diferentes aspectos como se describe a continuación.

\section{La célula como una celda}

Según Alzogaray (2006) sí se tuviera que nombrar a la primera persona que hizo un hallazgo en la búsqueda de la célula, esta persona debería ser el arquitecto Robert Hooke
(1635-1703), quién ayudó a reconstruir la ciudad de Londres, después del incendio de 1666. En este proceso además, por solicitud de la Royal Society, él construyó un laboratorio, donde inicio sus estudios en Biología, Medicina, astronomía, microscopia, entre otras disciplinas (Alzogaray, 2006).

Con el ánimo de satisfacer su curiosidad por lo desconocido, Hooke (1635-1703) construyó su propio microscopio, con el que aumentó la muestra unas 150 veces, lo que le permitió conocer y describir detalles de objetos y organismos. Entre estos objetos, un trozo de corcho, en el cual observó unos huecos, que comparó con un panal de abejas, Ilamándolo "célula". La descripción de Hooke (1635-1703) fue "es poroso y perforado, de un modo que recordaba un panal de abejas, pero los poros no eran regulares, los poros eran poco profundos" (Alzogaray, 2006).

Esta descripción fue posteriormente enriquecida por Trevinarus (1779-1864), quién además propuso que las células no eran simples cavidades, sino entidades reales que se podían aislar de los tejidos de los que formaban parte. Él además demostró que las plantas estaban recubiertas no por una membrana, sino por una capa de células.

\section{La membrana celular}

Años más tarde (1817) Johann Heinrich (1805-1877), estableció que el tejido celular constaba de dos vesículas separadas entre sí, pero que sus membranas solían hallarse tan estrechamente adosadas que parecían constituir tan sólo una simple red. Entonces de acuerdo con esto, concluyó que los tejidos estaban formados por células individuales que no eran huecas, puesto que en 1831 Brown (1773-1858), había redescubierto la presencia de un núcleo dentro de las células vegetales, respaldando lo expuesto por Heinrich (1805-1877). 
La historia de la ciencia en la enseñanza de la célula Laura Carrillo | Cristina Morales | Vania Pezoa | Johanna Camacho

En 1833 el químico Francés Francois Raspail (1794-1878), describió la célula vegetal como una especie de laboratorio de tejidos celulares que se organizan y desarrollan en su seno. Además, que tenían la particularidad de detener la propiedad de tomar por aspiración del líquido ambiente los elementos necesarios para la elaboración.

Hacia finales del siglo XVIII la variedad de formas de los seres vivos se transformó en un problema para la biología de la época, ya que a pesar, de que los organismos eran distintos presentaban partes elementales (células) iguales, antecedentes relevante para el surgimiento de la morfología.

\section{Los primeros pasos hacia la Teoría Celular}

Según Müller (1801-1858) todas las líneas de estudio, como la física, la química, la fisiología, la anatomía comparada, la microscopia, convergían en el mismo problema, mencionado en el Handbuch, la unidad esencial de los seres vivos "en el organismo, la unidad del todo gobierna a la reunión de partes heterogéneas" (Vial, 1999, p.29). Es decir, que el organismo estaba "formado por la agregación de partes iguales, y no de partes heterogéneas" (Vial, 1999, p.29). Pero un discípulo de Müller, el joven alemán Theodor Schwann (1810-1882), quien adelantaba su tesis Doctoral en Medicina, rechazó las ideas básicas de su maestro, las cuales se fundamentaban en que existe una fuerza vital que es capaz de actuar siguiendo un plan preestablecido. A partir de esto, Schwann (1810-1882), intenta hacer una teoría del organismo en la cual considera que:

"los distintos puntos de vista sobre las fuerzas fundamentales de los organismos se dejan reducir a dos que son esencialmente distintos. Según el primero, existe una fuerza subyacente a cada organismo, la cual le da forma de acuerdo con una idea preestablecida, y reúne las moléculas de tal manera que con ellas se puedan alcanzar los fines predeterminados por la idea [...] una fuerza así sería esencialmente distinta de todas las fuerzas de la naturaleza inorgánica, por cuanto en ésta sólo tiene lugar una operación ciega. En la naturaleza inorgánica a una determinada acción sigue en forma necesaria una modificación que está determinada cuantitativamente y cualitativamente, sin tomar en cuenta ninguna finalidad..." (Vial, 1999, p.32).

De este punto de vista, Schwann (18101882) propone una nueva idea, sustentada en que: "las fuerzas fundamentales de los organismos coinciden esencialmente con las fuerzas de la naturaleza inorgánica y que ellas operan en todo momento sin considerar ninguna finalidad. Se trata de fuerzas que están puestas junto con la existencia de la materia, tal como acontece con las fuerzas físicas" (Vial, 1999, p.33).

Entonces, sí en el organismo no opera una fuerza vital, éste opera de acuerdo con las propiedades de la materia que existe en cada organismo, donde esta materia no organizada sigue sus propias leyes de interacción, la cual configura a los organismos y a sus partes. Por tanto, la vida individual de las células tiene su causa en las fuerzas inherentes a cada una de las moléculas que las forman.

En Berlín Schwann (1810-1882) trabajó en conjunto con Schleiden (1804-1881), un botánico también alemán, interesado en el origen de las celdillas en organismos vegetales. El propósito de Schleiden (1804-1881) era explicar el rápido incremento de núcleos en los organismos y cómo alrededor de cada uno de éstos aparecía una membrana 
que terminara convirtiéndose en una nueva celdilla. Esto lo puedo explicar, afirmando que las celdillas se generaban por una especie de coagulación en el seno del material que llenaba la celdilla madre; luego, en uno de los polos del núcleo aparecía una vesícula aplanada. Junto con el aumento de la cavidad de la vesícula, la pared se iba engrosando hasta que quedaba formada la celdilla vegetal definitiva. De acuerdo con esto, el núcleo sería el órgano generador de la celdilla y por ello Schleiden (1804-1881) le dio el nombre de citoblasto.

Muchos de los aspectos propuestos por Schleiden (1804-1881), fueron considerados erróneos a partir de las investigaciones elaboradas en 1837 por Mohl (1805-1872) con el alga filamentosa spyrogyra. A pesar de esto, Schleiden acertó en que el núcleo era la estructura más importante en la división celular.

\section{El núcleo y el origen de la célula}

Las investigaciones de Schleiden (18041881), incentivaron el despertar de las ideas de Schwann (1810-1882) pues la descripción de la división celular en la cuerda dorsal de un renacuajo, que en alguna oportunidad Müller (1801-1858) le había mostrado, evidenciaba que las células se agrupaban en pares (de dos y cuatro), y los núcleos estaban juntos hacia las membranas de éstas. Schwann en sus propias palabras expuso que: "había reconocido el principio que está en el fondo del hecho, esto es, que dos tejidos radicalmente diferentes se desarrollan de idéntica manera... la acción de una ida para reunir a las moléculas. Éstas se juntan por sus propias fuerzas, las cuales son esencialmente las mismas en todas partes" (Vial, 1999, p.40). Una vez hecha esta analogía, estudió el cartílago de las branquias de los renacuajos donde observó estructuras similares y las dibujó, aunque estos dibujos estaban influenciados por los aspectos de
Scheleiden, que posteriormente se consideraron erróneos.

Tanto para Schwann (1810-1882) y Schleiden (1804-1881), el núcleo era una estructura fundamental en la estructura de la célula, si bien se consideró que las células se dividían a partir de un citoblastema, hoy se sabe que éstas se dividen a partir de una célula preexistente y esto se relacionado con las conclusiones de ellos.

Luego de este descubrimiento Schwann (1810-1882), al parecer no se tienen en cuenta más en la historia de la ciencia, pues no se observa evidencia de algún otro aporte. Se cree, que por problemas personales tuvo que salir de Alemania a Lieja donde ejerció como docente, dedicándose a las explicaciones filosóficas y teológicas de las propiedades de los átomos materiales. Este alejamiento, tuvo consecuencias importantes, ya que si bien se continuaba indagando sobre la estructura de la célula, sus aportes sólo eran parcialmente considerados.

La única parte de la teoría de Schwann (1810-1882) que podía ser sometida al control de la experiencia era la del origen de la célula. Veinte años más tarde, otro discípulo de Müller, Remak (1815-1865) concluyó que todas las celdillas vegetales se originaban en el interior de otras celdillas y en 1852 comunicó que en el embrión de anfibio, las células se generaban por divisiones sucesivas, con lo cual creía suficiente para enmendar los errores de Schwann (1810-1882). Sin embargo, los trabajos de Virchow (18211902), mostraban argumentos que no lo confirmaban mediante sus estudios en 1850 sobre la tuberculosis. Él observó que estos estaban formados únicamente por células, por lo que no se podía señalar que existiera un citoblastema amorfo a partir del cual se originaran las células. En 1852, las células 
La historia de la ciencia en la enseñanza de la célula Laura Carrillo | Cristina Morales | Vania Pezoa | Johanna Camacho

eran entendidas como algo natural y sencillo, donde cada una era una unidad vital que ejercía su influencia sobre el territorio que la rodeaba, además del hecho que las células se originaban por "divisiones y fragmentaciones", esto Virchow lo expuso de la siguiente forma:

"la naturaleza orgánica no tiene individuos absolutos, átomos orgánicos: en toda ellas se manifiesta el principio de la capacidad de división y fragmentación" y "el mundo orgánico, animado, se distingue de lo inorgánico... por la producción de unidades capaces de dividirse" (Vial, 1999, p.56).

Así, según lo expuesto por Virchow (1821-1902), el centro de la vida autónoma de las partes del organismo no es otro que la célula y el único papel que tiene la sangre es de nutrirla. Es así como Virchow (18211902) redefine la célula: "es para sí misma, estimulo y acción... una unidad cerrada, que ha recibido el principio de su vida, que llena en si misma las leyes de su existencia" (Vial, 1999, p.59). Esta definición, se retomó cinco años más tarde por Franz Leydig (1821-1908) así:"las células son los más pequeños cuerpos orgánicos, que poseen un centro activo que relaciona a todas sus parte consigo mismo y sus necesidades" (Vial, 1999, p.59).

\section{Los componentes fundamentales de la célula}

Franz Leydig (1821-1908) en 1857 demostró que los componentes fundamentales de la célula eran: la membrana, el contenido y el núcleo. Pero, el contenido era el más difícil de identificar, ya que no era igual en todas las células, es en estas circunstancias en la que se considera la existencia del protoplasma y Max Schultze (1825-1874), hizo un paralelo con lo que en un protozoo se denomina sarcoda. Pero no fue este el que logró identificar la diferencia, sino el zoólogo francés Félix Dujardi (1801-1860) en 1835. Dujardi describió que el sarcoda era un material gelatinoso, insoluble en agua, adherente y retráctil, que son características que no definen la vida, sino que es la irritabilidad, la propiedad más propia de la vida, lo que se trataba de señalar desde tiempos de Haller y Brown (1773-1858).

Max Schultze (1825-1874), retoma lo propuesto por Dujardi (1801-1860) y Mohl (1805-1872) y estudia las fibras musculares, elemento contráctil de los animales superiores, donde cada fibra muscular es una sola célula provista de varios núcleos y está constituida por largos filamentos contráctiles. Para Schultze (1805-1872), el conjunto formado por cada núcleo y la sustancia homogénea correspondía a una célula, donde no era posible observar una membrana y de acuerdo con esto formuló otra definición de célula: "una pequeña masa de protoplasma desnudo, que contienen un núcleo" (Vial, 1999, p.66).

A pesar de la importancia de lo propuesto por Max Schultze (1805-1872), esta afirmación no era factible de generalizar, pues no todas las células tienen núcleo, la membrana es un componente fundamental de cada célula y el protoplasma hasta entonces no fue posible definirlo sobre una concepción científica rigurosa.

A partir de los antecedentes descritos, en 1839 Schwann y Schleiden, publican las siguientes conclusiones sobre la Estructura de la Célula (Alzogaray, 2006):

- Las células son partes elementales de los tejidos animales y vegetales.

- No es la membrana la que define a la célula, sino su contenido. Una masa de materia viva con su núcleo. 
- Los procesos de nutrición y crecimiento de las células animales y vegetales son similares.

- Las células se forman a partir de una sustancia amorfa, que crece en todas direcciones, generando primero el núcleo y luego, el resto de la célula.

\section{La teoría celular}

En 1850 los médicos Virchow (1821-1902), Remak (1815-1865) y Kolliker (1817-1905) evidenciaron que las células se generaban por división de células preexistentes. Brucke en 1861 al reflexionar sobre las relaciones entre las funciones orgánicas y estructura celular, concluye que la célula está compuesta por organismos más pequeños que ésta, las cuales son a la célula como ésta es al organismo.

A partir de estas ideas se formuló la teoría celular, la cuál se puede resumir en los siguientes postulados, según Alzogaray (2006):

- La célula es la unidad fundamental de todos los seres vivos.

- Las células se multiplican por división.

- Las células están rodeadas por una membrana con un núcleo.

- Las células poseen material genético que se transmite de una generación a otra.

- Todas las células tienen la misma composición química.

- Dentro de las células tiene lugar el flujo de energía que permite a los organismos crecer y mantenerse con vida.
Por tanto, con los trabajos de Virchow (1821-1902) se observa gran progreso en el estudio de la célula, esto debido al valor y uso que se otorgó a los microscopios, perfeccionándolos cada vez más, lo que hizo posible que se observara con mayor detenimiento el núcleo y las transformaciones de éste. Fue Schneider (1898-1924) en 1873, quien realizó una descripción ordenada de la estructura del núcleo, mostrando que los cromosomas se disponen en el ecuador de la célula para luego distribuirse hacia los polos. Esta importante conclusión, permitió que en 1875 Strarburger (1844-1912) comprobara que esa era la forma universal en que se producía la división celular, tanto en animales como en plantas y en 1879 Flemming (1843-1905) registró que cada cromosoma se dividía longitudinalmente en dos, haciendo que existan dos porciones idénticas en los núcleos hijos. En 1875 Hertwig (1850-1937), mostró que durante la fecundación se fusionan tanto un núcleo aportado por la madre como por el padre, así Van Beneden (1846-1910) pudo identificar que cada uno de los núcleos poseía la mitad del material genético. De acuerdo con esto, se deduce que tanto el padre como la madre aportan a la progenie la mitad de su material.

Luego de los experimentos de Urey (1893-1981) y Miller (1930 - 2007), se concluyó que la vida había surgido de reacciones químicas, siendo lo más complicado de aceptar la composición de dicha molécula que la ocasionaba, el ácido desoxirribonucleico (ADN), una estructura análoga a una inmensa biblioteca de genes, los cuales son manuales de instrucciones, de acuerdo con esto se consideró que cada célula que posea núcleo va a poseer ADN, donde el ácido ribo- 
La historia de la ciencia en la enseñanza de la célula Laura Carrillo | Cristina Morales | Vania Pezoa | Johanna Camacho

nucleico (ARN) es su precursor o manual. A través de estas nuevas evidencias, se acordó que el proceso de la formación del ADN ocurre así:

- Se fotocopia un manual.

- La fotocopia es envidiada a un lugar donde se elaboran las proteínas.

- Siguiendo las instrucciones de la fotocopia se elaboran las proteínas.

En el siglo XX a partir de estudios que diferenciaban las bacterias de las células animales y vegetales, fue posible concluir que estas últimas poseen un complejo sistema de membranas internas que delimitan varios compartimientos y en cada uno de ellos, se lleva a cabo un trabajo diferente: respirar, fabricar azúcares o proteínas y degradar cuerpos extraños. Además, que los genes no se encontraban desnudos dispersos por el citoplasma como se creía, sino que dentro de organelos como las mitocondrias y los cloroplastos.

También, se definieron las mitocondrias como corpúsculos presentes en casi todas las células con núcleo, en su interior tiene lugar la respiración celular, por lo que se les conoce como "el motor de las células". Mientras hay células que poseen sólo una mitocondria, otras contienen cientos. Los cloroplastos, se encuentran en las células de las plantas y de algunos organismos unicelulares con núcleo. Dentro de los cloroplastos ocurre la fotosíntesis: la conversión de la energía solar en energía química. Otro aporte que se hace respecto a las células es que algunas poseen flagelo, como por ejemplo los espermatozoides, donde esta estructura les sirve para movilizarse.

Los aportes señalados anteriormente, permiten comprender cómo se construyo la teoría celular y cómo las diferentes explicaciones acerca de su estructura y funciones, permite demostrar diferentes procesos contextuales, conceptuales y procedimentales. En la Tabla 1, se presentan las principales conclusiones y conceptos relacionados, lo que permite tener una visión general acerca de la Evolución de la Teoría Celular.

\section{La historia de la célula en los libros de texto}

La célula como concepto científico, tiene gran significado no sólo para el desarrollo de la biología como disciplina científica, sino además para su enseñanza tanto a nivel secundario (básica) y medio. La teoría celular se ha constituido como un contenido curricular obligatorio ya que condiciona y articula la comprensión de los conceptos biológicos (Rodríguez y Moreira, 2002). Además, se entiende que la célula es un concepto clave en la conceptualización y articulación de la biología escolar, por ello se propone a continuación un análisis exploratorio para evidenciar que historia de la célula se considera en el currículo chileno, a través de los libros de texto que promueve el Ministerio de Educación Nacional (MINEDUC) desde sexto año básico hasta cuarto año de Educación Media. Los principales resultados, se describen en la Tabla 2. 


\begin{tabular}{|c|c|c|c|}
\hline Año & Persona & Descripción sobre la célula & $\begin{array}{l}\text { Concepto } \\
\text { relacionado }\end{array}$ \\
\hline 1665 & $\begin{array}{c}\text { Hooke } \\
(1635-1703)\end{array}$ & $\begin{array}{l}\text { Observó un trozo de corcho, en el cual } \\
\text { habían unos huecos, que comparó a un } \\
\text { panal de abejas, llamándolo "celdilla". }\end{array}$ & Estructura general \\
\hline 1802 & $\begin{array}{l}\text { Trevinarus } \\
(1779-1864)\end{array}$ & $\begin{array}{l}\text { Propuso que las células eran entidades } \\
\text { reales que se podían aislar de los tejidos } \\
\text { de los que formaban parte. }\end{array}$ & Estructura general. \\
\hline 1817 & $\begin{array}{r}\text { Heinrich } \\
(1805-1877)\end{array}$ & $\begin{array}{l}\text { Los tejidos estaban formados por células } \\
\text { individuales que no eran huecas. }\end{array}$ & Estructura general. \\
\hline 1831 & $\begin{array}{c}\text { Brown } \\
(1773-1858)\end{array}$ & $\begin{array}{l}\text { Redescubrió la presencia de un núcleo } \\
\text { dentro de las células vegetales. }\end{array}$ & Estructura general. \\
\hline 1833 & $\begin{array}{c}\text { Raspail } \\
(1794-1878)\end{array}$ & $\begin{array}{l}\text { Las células toman por aspiración } \\
\text { del líquido ambiente los elementos } \\
\text { necesarios para su elaboración. }\end{array}$ & $\begin{array}{l}\text { Estructura general e } \\
\text { intercambio medio } \\
\text { interno - externo. }\end{array}$ \\
\hline 1835 & $\begin{array}{c}\text { Dujardi } \\
(1801-1860)\end{array}$ & $\begin{array}{l}\text { Describió que el sarcoda es un material } \\
\text { gelatinoso, insoluble en agua, adherente } \\
\text { y retráctil. }\end{array}$ & Estructura general. \\
\hline 1837 & $\begin{array}{c}\text { Mohl } \\
(1805-1872)\end{array}$ & $\begin{array}{l}\text { Hizo una buena descripción de la } \\
\text { división celular en el alga filamentosa } \\
\text { spyrogyra. }\end{array}$ & $\begin{array}{l}\text { Estructura general y } \\
\text { unidad de origen }\end{array}$ \\
\hline 1850 & $\begin{array}{c}\text { Virchow (1821- } \\
\text { 1902), Remak } \\
(1815-1865) \text { y } \\
\text { Kolliker (1817- } \\
\text { 1905) }\end{array}$ & $\begin{array}{l}\text { Las células se generan por división de } \\
\text { células preexistentes. }\end{array}$ & Unidad de origen. \\
\hline 1839 & $\begin{array}{l}\text { Schleiden } \\
(1804-1881) \text { y } \\
\text { Schwann } \\
(1810-1882)\end{array}$ & $\begin{array}{l}\text { Las células son partes elementales de } \\
\text { los tejidos animales y vegetales. No es la } \\
\text { membrana la que define a la célula, sino } \\
\text { una masa de materia viva con su núcleo. } \\
\text { Los procesos de nutrición y crecimiento } \\
\text { de las células animales y vegetales son } \\
\text { similares. Las células se forman a partir } \\
\text { de una sustancia amorfa, que crece en } \\
\text { todas direcciones, generando primero } \\
\text { el núcleo y luego el resto de la célula. }\end{array}$ & $\begin{array}{c}\text { Estructuras } \\
\text { generales, } \\
\text { intercambio medio } \\
\text { interno - externo, } \\
\text { unidad estructural, } \\
\text { unidad funcional y } \\
\text { unidad de origen }\end{array}$ \\
\hline 1852 & $\begin{array}{c}\text { Remak } \\
(1815-1865)\end{array}$ & $\begin{array}{l}\text { Comunicó que en el embrión de anfibio } \\
\text { las células se generaban por divisiones } \\
\text { sucesivas. }\end{array}$ & $\begin{array}{l}\text { Unidad estructural y } \\
\text { unidad de origen. }\end{array}$ \\
\hline
\end{tabular}


La historia de la ciencia en la enseñanza de la célula Laura Carrillo | Cristina Morales | Vania Pezoa | Johanna Camacho

\begin{tabular}{|c|c|c|c|}
\hline Año & Persona & Descripción sobre la célula & $\begin{array}{l}\text { Concepto } \\
\text { relacionado }\end{array}$ \\
\hline 1857 & $\begin{array}{l}\text { Franz Leydig } \\
(1821-1908)\end{array}$ & $\begin{array}{l}\text { Los componentes fundamentales de la } \\
\text { célula son la membrana, el contenido y } \\
\text { el núcleo. }\end{array}$ & Estructura general. \\
\hline 1858 & $\begin{array}{l}\text { Virchow }(1821- \\
1902)\end{array}$ & $\begin{array}{l}\text { La célula es una unidad vital que } \\
\text { ejercía su influencia sobre el territorio } \\
\text { que la rodeaba, además las células } \\
\text { se originaban por "divisiones y } \\
\text { fragmentaciones". }\end{array}$ & $\begin{array}{l}\text { Unidad estructural y } \\
\text { unidad de origen. }\end{array}$ \\
\hline 1861 & $\begin{array}{l}\text { Max Schultze } \\
(1825-1874)\end{array}$ & $\begin{array}{l}\text { El conjunto formado por cada núcleo y } \\
\text { la sustancia homogénea corresponde a } \\
\text { una célula }\end{array}$ & Estructura general \\
\hline 1861 & Brucke & $\begin{array}{l}\text { La célula estácompuesta pororganismos } \\
\text { más pequeños que ésta. }\end{array}$ & $\begin{array}{l}\text { Estructuras } \\
\text { principales }\end{array}$ \\
\hline 1873 & $\begin{array}{l}\text { Schneider } \\
(1898-1924)\end{array}$ & $\begin{array}{l}\text { Los cromosomas se disponen en } \\
\text { el ecuador de la célula para luego } \\
\text { distribuirse a los polos. }\end{array}$ & $\begin{array}{l}\text { Estructuras } \\
\text { generales, } \\
\text { principales y unidad } \\
\text { de origen. }\end{array}$ \\
\hline 1875 & $\begin{array}{l}\text { Strarburger } \\
(1844-1912)\end{array}$ & $\begin{array}{l}\text { Los cromosomas se disponen en el } \\
\text { ecuador y luego migran a los polos } \\
\text { tanto en vegetales como en animales. }\end{array}$ & Unidad de origen. \\
\hline 1875 & $\begin{array}{l}\text { Hertwig } \\
\text { (1850-1937) y } \\
\text { Van Beneden } \\
(1846-1910)\end{array}$ & $\begin{array}{l}\text { Durante la fecundación se fusionan } \\
\text { tanto un núcleo aportado por la madre } \\
\text { como por el padre, donde cada uno } \\
\text { aporta a la progenie la mitad de su } \\
\text { material. }\end{array}$ & $\begin{array}{l}\text { Unidad hereditaria y } \\
\text { de origen. }\end{array}$ \\
\hline 1879 & $\begin{array}{l}\text { Flemming } \\
(1843-1905)\end{array}$ & $\begin{array}{l}\text { Registró que cada cromosoma se divide } \\
\text { longitudinalmente en dos, haciendo } \\
\text { que existan dos porciones idénticas en } \\
\text { los núcleos hijos. }\end{array}$ & $\begin{array}{l}\text { Unidad hereditaria y } \\
\text { de origen. }\end{array}$ \\
\hline
\end{tabular}

Tabla 1. Reseña entre 1665 y 1879, sobre los principales hechos que conllevaron a la formulación de la Teoría Celular. 


\begin{tabular}{|c|c|c|c|}
\hline Sector & Nivel & $\begin{array}{l}\text { Contenido mínimo obligatorio } \\
\text { (CMO) }\end{array}$ & $\begin{array}{l}\text { Revisión textos. } \\
\text { Incorporación historia de la } \\
\text { célula }\end{array}$ \\
\hline $\begin{array}{l}\text { Ciencias } \\
\text { Naturales }\end{array}$ & $\begin{array}{l}\text { Sexto } \\
\text { básico }\end{array}$ & $\begin{array}{l}\text { "Identificación de los niveles de } \\
\text { organización de los seres vivos, } \\
\text { desde célula hasta organismo } \\
\text { pluricelular (célula, órgano, } \\
\text { sistema, organismo), y la relación } \\
\text { existente entre estos niveles" }\end{array}$ & $\begin{array}{l}\text { MINEDUC (2010a) No presenta } \\
\text { información referente a la } \\
\text { historia de la ciencia. }\end{array}$ \\
\hline $\begin{array}{l}\text { Ciencias } \\
\text { Naturales }\end{array}$ & $\begin{array}{l}\text { Séptimo } \\
\text { básico }\end{array}$ & $\begin{array}{l}\text { No aparecen CMO en relación } \\
\text { con la Célula. }\end{array}$ & $\begin{array}{l}\text { MINEDUC (2010b) No presenta } \\
\text { información referente a la } \\
\text { historia de la ciencia. }\end{array}$ \\
\hline $\begin{array}{l}\text { Ciencias } \\
\text { Naturales }\end{array}$ & $\begin{array}{l}\text { Octavo } \\
\text { básico }\end{array}$ & $\begin{array}{l}\text { “Descripción de la estructura } \\
\text { y función global de la célula, } \\
\text { incluyendo su función como } \\
\text { portadora de material genético. } \\
\text { Descripción de la función } \\
\text { integrada de los sistemas } \\
\text { circulatorio, respiratorio y } \\
\text { digestivo como proveedores } \\
\text { de gases y nutrientes a las } \\
\text { células; y del sistema excretor } \\
\text { en la eliminación de desechos } \\
\text { provenientes de la célula" }\end{array}$ & $\begin{array}{l}\text { MINEDUC (2010c)Unidad I: } \\
\text { Unidad fundamental de los } \\
\text { seres vivos } \\
\text { Pág.12 } \\
\text { Aportes conceptuales de: } \\
\text { - Hooke } \\
\text { - Schleiden } \\
\text { - Schwann }\end{array}$ \\
\hline
\end{tabular}


La historia de la ciencia en la enseñanza de la célula Laura Carrillo | Cristina Morales | Vania Pezoa | Johanna Camacho

\begin{tabular}{|c|c|c|c|}
\hline Sector & Nivel & $\begin{array}{l}\text { Contenido mínimo obligatorio } \\
\text { (CMO) }\end{array}$ & $\begin{array}{l}\text { Revisión textos. } \\
\text { Incorporación historia de la } \\
\text { célula }\end{array}$ \\
\hline Biología & $\begin{array}{l}\text { Primer Año } \\
\text { Medio }\end{array}$ & $\begin{array}{l}\text { Identificación de las principales } \\
\text { moléculas orgánicas que } \\
\text { componen la célula y de sus } \\
\text { propiedades estructurales y } \\
\text { energéticas en el metabolismo } \\
\text { celular. } \\
\text { Explicación del funcionamiento de } \\
\text { los tejidos y órganos basada en la } \\
\text { actividad de células especializadas } \\
\text { que poseen una organización } \\
\text { particular, por ejemplo, la célula } \\
\text { secretora, la célula muscular. } \\
\text { Explicación de fenómenos } \\
\text { fisiológicos sobre la base de la } \\
\text { descripción de mecanismos } \\
\text { de intercambio entre la célula } \\
\text { y su ambiente (transporte } \\
\text { activo, pasivo y ósmosis) y } \\
\text { extrapolación de esta información } \\
\text { a situaciones como, por ejemplo, la } \\
\text { acumulación o pérdida de agua en } \\
\text { tejidos animales y vegetales. }\end{array}$ & $\begin{array}{l}\text { MINEDUC (2010d) Unidad I: } \\
\text { La célula unidad básica de los } \\
\text { seres vivos. } \\
\text { Pág.12 } \\
\text { Aportes conceptuales de: } \\
\text { - Schleiden } \\
\text { - Schwann } \\
\text { - Virchow. } \\
\text { Pág. 52- 53 } \\
\text { Biología en la historia. } \\
\text { Revisión histórica de los } \\
\text { aportes realizados en la } \\
\text { historia de la célula } \\
\text { - } \quad \text { (1665-2007). } \\
\text { - } \quad \text { Sooke } \\
\text { - Schleiden } \\
\text { - } \quad \text { Virchown } \\
\text { - } \quad \text { Kuhne } \\
\text { - } \quad \text { Avery }\end{array}$ \\
\hline Biología & $\begin{array}{l}\text { Segundo } \\
\text { Año Medio }\end{array}$ & $\begin{array}{l}\text { Explicación del mecanismo } \\
\text { que permite la conservación de } \\
\text { la información genética en el } \\
\text { transcurso de la división celular } \\
\text { (mitosis) y de la generación de } \\
\text { células haploides (meiosis), en la } \\
\text { gametogénesis. }\end{array}$ & $\begin{array}{l}\text { MINEDUC (2010e) No presenta } \\
\text { información referente a la } \\
\text { historia de la ciencia. }\end{array}$ \\
\hline Biología & $\begin{array}{l}\text { Tercer Año } \\
\text { Medio }\end{array}$ & $\begin{array}{l}\text { Identificación de la neurona } \\
\text { como la unidad estructural } \\
\text { y funcional del sistema } \\
\text { nervioso, su conectividad y su } \\
\text { participación en la regulación } \\
\text { e integración de funciones } \\
\text { sistémicas como, por ejemplo, la } \\
\text { circulación y la respiración. }\end{array}$ & $\begin{array}{l}\text { MINEDUC (2010f) No presenta } \\
\text { información referente a la } \\
\text { historia de la ciencia. }\end{array}$ \\
\hline Biología & $\begin{array}{l}\text { Cuarto Año } \\
\text { Medio }\end{array}$ & $\begin{array}{l}\text { No se presentan CMO en relación } \\
\text { con la célula. }\end{array}$ & $\begin{array}{l}\text { MINEDUC }(2010 \mathrm{~g}) \text { No presenta } \\
\text { información referente a la } \\
\text { historia de la ciencia. }\end{array}$ \\
\hline
\end{tabular}

Tabla 2: Análisis exploratorio del tema célula en los libros de texto, que propone el MINEDUC. 
De acuerdo con el análisis anterior, se evidencia que la célula se considera desde la estructura y funcionamiento de todo el mundo vivo. Se relacionan principalmente aspectos de la célula que fueron abordados por Hooke en 1665, Schleiden y Schwann en 1839, Virchow en 1858 y otros, que sí bien permitieron comprender la célula como unidad vital de los seres vivos, no permiten comprender cómo es su estructura general, función general, funciones específicas de los organelos y la relación entre el medio internoexterno. Aspectos, que presentan mayor dificultad para el aprendizaje del estudiantado, según la investigación de Arzola et al (2011).

Llama la atención que se incorporen sólo antecedentes históricos en algunos niveles (Octavo Básico, Primero Medio) y en otros no (Sexto y Séptimo Básico; Segundo, Tercero y Cuarto Medio), siendo que el concepto de célula es un contenido científico que se desarrolla progresivamente a través del currículo chileno, según el MINEDUC (2009). Sin embargo, los aspectos que se incorporan se centran principalmente en la definición de algunos conceptos del siglo $\mathrm{XIX}$, pero no se relacionan para comprender cómo se construyó y consensúo la teoría celular sino como definiciones de la célula.

En particular, no se observa información sobre la célula como unidad hereditaria de origen, ni tampoco acerca de la estructura y función de los organelos celulares, lo que se sustenta en la nula incorporación de los aportes de personas como Strarburger (1844-1912), Hertwing (1850-1937), Van Beneden (1846-1910), quienes trataron de comprender cómo se dividían las células y cuyas conclusiones, sólo se consolidaron durante el siglo XX.

Así, se da cuenta que las dificultades de comprensión y de interpretación del mundo vivo en función de los problemas de conceptualización de la célula continúan siendo objeto de estudio, como lo demuestran las investigaciones adelantadas por Rodríguez y Moreira (1999), Rivarosa (2009), Soares (2008), (Shuster, 1999) que señalan las principales dificultades del estudiantado frente a este concepto y otras investigaciones, como la de Arzola et al (2011), quienes señalan la relación entre la propia construcción de la historia del concepto y la construcción del modelo teórico de célula por el estudiantado, donde la historia y epistemología de las ciencias, resultan fundamental para comprender dichos procesos.

Para ello, es necesario desarrollar nuevas propuestas didácticas, que intencionen dichos componentes, por ejemplo en la investigación de Arzola et al (2011), se propone una unidad didáctica bajo el Modelo Cognitivo de Ciencia promoviendo en el estudiantado construir su conocimiento a partir de sus ideas previas, formulación de hipótesis, identificación de distintos puntos de vista y resolución de problemas. Las principales conclusiones, mostraron que los modelos científicos del estudiantado corresponden a los más tradicionales de la ciencia, lo que se relaciona directamente con los modelos científicos de la célula que aparecen en los libros de texto, según el análisis propuesto.

Por lo anterior, se considera finalmente que una comprensión completa de la biología escolar requiere el estudio de la historia y epistemología de las ciencias (Rodríguez, 2000). Así, la enseñanza - aprendizaje de la célula como concepto científico y escolar, no se realiza de forma descontextualizada o ahistórica, sino que debe promover que el estudiantado comprenda que el conocimiento científico es una creación humana y cómo tal está sujeta al contexto social, histórico y cultural en el que se encuentra inmerso el científico (Camacho, 2010). 
La historia de la ciencia en la enseñanza de la célula Laura Carrillo | Cristina Morales | Vania Pezoa | Johanna Camacho

"El conocimiento científico se ha ido construyendo a través de los siglos y las culturas, sobre cimientos que han estado condicionados o muchas veces determinados por creencias, prejuicios, conflictos de poder, influencias religiosas, crisis políticas y porque no decirlo, eventualmente fue el propio azar el que orientó las rutas del saber y del conocer, tomando estos caminos impensables en determinadas épocas" (Quintanilla, 2007, p. 6).

\section{Conclusiones y reflexiones finales}

Consideramos importante conocer la construcción del concepto de célula, puesto que este proceso implicó la dedicación de muchas personas a través de diferentes períodos de tiempo, entendiendo que no fue un proceso lineal, sino que fue matizado por la historia externa de cada contexto y la historia interna de los científicos que contribuyeron, rescatando los aportes de otros y adhiriéndose a estos conocimientos para construir su propio conocimiento. Bajo esta perspectiva y en acuerdo con Camacho (2010), se puede afirmar que la historia de la ciencia en la enseñanza de la Biología, invita a desarrollar nuevas prácticas del profesorado, nuevas estrategias en donde éstos pueden reorientar sus prácticas y generar competencias científicas, de tal manera que comprendan cómo se construye el conocimiento científico, siendo capaces de construir explicaciones o argumentos científicos para dar cuenta de la naturaleza humana y pragmática de la ciencia (Toulmin, 1977).

A fin de hacer posible una mirada de la enseñanza de las biología desde la historia de la Ciencia, a continuación se proponen algunos directrices a considerar en la sala de clases según los planteamientos de Rivarosa (2009):
- Analizar desde la historia de la ciencia la evolución conceptual de las teorías Biológicas.

- Identificar las dimensiones, errores y dificultades de comprensión de las teorías biológicas en distintas épocas y contextos socio-culturales.

- Conocer las características básicas de la metodología de investigación científica como estudio metódico, crítico y reflexivo.

- Desarrollar una actitud positiva ante la ciencia y a la vez crítica frente a los principios éticos que sustenta su quehacer científico.

Para lograr que las directrices anteriores sean posibles en la enseñanza de la célula, se pueden proponer actividades científicas, como las que propone Camacho (2009):

- Explicar historias contextualizadas, utilizadas desde un punto de vista didáctico - histórico-epistemológico, para introducir conceptos científicos, para motivar, para promover determinadas actitudes y valores hacia la ciencia, para relacionar conocimientos de diferentes áreas, fundamentando así el carácter interdisciplinario.

- Dramatizaciones de situaciones históricas, de debate, en las cuales el estudiantado exprese y argumente sus ideas. Por ejemplo, un grupo de estudiantes será partidario de las ideas de Müller, mientras que otro grupo defenderá las ideas de Hooke.

- Repetición de prácticas experimentales, de esta forma el estudiantado podrá demostrar cuáles eran las ideas científicas en el tiempo que se postularon, las 
estrategias de divulgación que utilizaron, las posibilidades de interpretación que se tenían con los instrumentos disponibles y la utilidad de las mismas para el avance teórico, superando las limitaciones de un análisis centrado en si las teorías científicas "eran verdad o no lo eran" en determinadas épocas (Izquierdo, 2000).

- Identificar y describir instrumentos científicos, mediante imágenes de revistas científicas y/o de divulgación, libros de texto o sitios en internet. Reflexionar sobre cuáles son los materiales con que fueron elaborados, como se divulgaron, que ideas aportaron, las controversias o polémicas que atenuaban. Por ejemplo, la elaboración del microscopio, desde sus comienzos, sus avances etc.

- Leer textos históricos seleccionados, de esta forma se pretende hacer ver que los libros siempre se escriben pensando en quien los ha de leer y que reflejan los valores y cultura de la época.

- Dar a conocer personajes históricos que muestren los aspectos humanos de las ciencias y el conjunto de valores en los que se desarrollan y que normalmente no aparecen o atenúan los libros de texto.

Finalmente, en acuerdo con la investigación en Didáctica de las Ciencias Experimentales y como lo han planteado diferentes especialistas (Camacho y Quintanilla, 2008; Izquierdo, Vallverdú, Quintanilla y Merino, 2006) es necesario el desarrollo de un modelo teórico- metodológico para incorporar la historia de la ciencia no solo en la sala de clases, si no que resulta inminente incorporarlo en la formación docente del profesorado, puesto que se ha evidenciado que durante el transcurso de la clase cada estudiante construye el conocimientos científico escolar a partir de los libros de texto, sin que se les proporcione un conocimiento profundo de cómo se construyeron las ideas allí presentadas, cuáles fueron las motivaciones personales o sociales que suscitaron dicho conocimientos, los conflictos éticos y los métodos de búsquedas. De esta manera, se podrá incentivar al estudiantado hacia el aprendizaje científico como un proceso problemático que implica la construcción de modelos teóricos sobre el mundo natural.

\section{Bibiografia}

Adúriz Bravo, A. (2000). Actualización en Didáctica de las Ciencias Naturales y las matemáticas. Colombia: Editorial Magisterio.

Alzogaray, R. (2006). Historia de las células. Buenos Aires: Capital Intelectual.

Arzola, et al. (2011). Los modelos explicativos de Célula Eucarionte Animal, que reconstruye el estudiantado de octavo básico de un colegio particular subvencionado de la comuna de Maipú, al desarrollar una unidad didáctica desde el modelo cognitivo de ciencia. Tesis de Licenciatura para la obtención del titulo de Licenciatura en Ciencias de la Educación Universidad Central de Chile. Santiago: Chile.

Camacho, J. (2010). Concepciones del profesorado y promoción de la explicación científica en la actividad química escolar. Aportes de un modelos de intervención desde la Historia de la Ciencia para la enseñanza de la electroquímica. Tesis de doctorado para la obtención del titulo de Doctora en Ciencias de la Educación. Pontificia Universidad Católica de Chile. Santiago: Chile.

Camacho, J. (2009). Ley Periódica. Una Unidad Didáctica desde la Historia de la Ciencia para la Enseñanza de la Química. En: Quintanilla, M. y Angulo, F. (Ed.), Unidades Didácticas en Química y Biología. Su contribución a la promoción de competencias de pensa- 
La historia de la ciencia en la enseñanza de la célula Laura Carrillo | Cristina Morales | Vania Pezoa | Johanna Camacho

miento Científico. (pp.207-228).Santiago de Chile, Chile: Conocimiento S.A.

Camacho, J. \& Quintanilla, M. (2008). Resolución de problemas científicos desde la Historia de la Ciencia. Retos y desafíos para promover competencias cognitivo lingüísticas en la química escolar. Ciência \& Educação, v. 14, n. 2, 197-212.

Echeverría, J. (1995). Filosofía de la Ciencia. Madrid: Akal Ediciones.

Izquierdo, M. \& Adúriz-Bravo, A. (2003). Epistemological foundations of school science. Science \&Education 12, 27 - 43.

Izquierdo, M. (2000) Fundamentos epistemológicos. Cap.2. En Perales, F.J. y Cañal, P. (eds). Didáctica de las Ciencias Experimentales. Teoría y Práctica de la Enseñanza de las Ciencias, 35- 64. Alcoy: Marfil, Madrid.

Izquierdo, M., Vallverdú, J., Quintanilla, M. y Merino, C. (2006). Relación entre la historia y la filosofía de las ciencias II. Alambique 48. 78-91.

Matthews, M. (1994) Science Teaching. The Role of History and Philosophy Science. New York : Routledge.

MINEDUC, (2009). Ajuste curricular en el sector de Ciencias Naturales. Santiago: Unidad de Curriculo y Evaluación.

MINISTERIO DE EDUCACIÓN (2010a) "Naturaleza 6" Texto para el estudiante, sexto año básico, Editorial Pearson Scott Foresman. Chile

MINISTERIO DE EDUCACIÓN (2010b) "Naturaleza 7" Texto para el estudiante, séptimo año básico, Editorial Santillana. Chile

MINISTERIO DE EDUCACIÓN (2010c) "Naturaleza 8" Texto para el estudiante, octavo año básico, Editorial Santillana. Chile

MINISTERIO DE EDUCACIÓN (2010d) "Biología" Texto para el estudiante, primer año medio, Editorial Santillana. Chile

MINISTERIO DE EDUCACIÓN (2010e) "Biología" Texto para el estudiante, segundo año medio, Editorial McGrawHill . Chile
MINISTERIO DE EDUCACIÓN (2010f) "Biología" Texto para el estudiante, tercer año medio, Editorial Santillana. Chile

MINISTERIO DE EDUCACIÓN (2010g) "Biología" Texto para el estudiante, cuarto año medio, Editorial Santillana. Chile

Quintanilla, M. (2007). La enseñanza del modelo atómico de John Dalton desde una visión naturalizada de la Historia de la Química. En: Quintanilla, M. (Ed.), Historia de la Ciencia. Aportes para su divulgación y enseñanza. Volumen II. (pp.68-84).Santiago de Chile, Chile: Arrayán.

Rivarosa, A. (2009). Aprendiendo a enseñar: La reflexión histórica y epistemológica en la formación de formadores. Argentina: Universidad Nacional de Río Cuarto.

Rodríguez, M. (2000). Modelos mentales de célula. Una aproximación a su tipificación con estudiantes de COU. Tesis de doctora para la obtención del título de Doctor en Didáctica de las Ciencias Experimentales. Universidad de La Laguna: España.

Rodríguez, M. y Moreira, M (1999). Modelos mentales de la estructura y el funcionamiento de la célula: dos estudios de casos. Investigações em Ensino de Ciencias, 4 (2), 121-160.

Rodríguez, M. y Moreira, M. A. (2002). Modelos mentales VS. esquemas de célula. Investigações. em Ensino de Ciências, 7 (1), 77-103.

Schuster, F. (1999). Los laberintos de la contextualización de la ciencia. En: Althabe, G. y Schuster, F. (comp.) Antropología del Presente. Buenos Aires: Edicial.

Soares, F. et al (2008). Estratégia didática com uso de analogias no ensino de biologia celular. Revista Brasileira de Biociências, 6 (1), 37-38.

Toulmin, S. (1977). La comprensión humana. Vol.1 El uso colectivo y la evolución de los conceptos. Madrid: Alianza editorial.

Vial, J. (1999). Historia de la Célula. Santiago: Universitaria. 